\title{
Novel mutations of STXBP2 and LYST associated with adult haemophagocytic lymphohistiocytosis with Epstein-Barr virus infection: a case report
}

\author{
Lingshuang Sheng, Wei Zhang, Jia Gu, Kefeng Shen, Hui Luo and Yang Yang * (D)
}

\begin{abstract}
Background: Haemophagocytic lymphohistiocytosis is a life-threatening disease resulting from primary or secondary hyper-inflammatory disorders. The typical symptoms include persistent fever, splenomegaly, cytopenia and significant elevation of serum ferritin.

Case presentation: We report a 30-year-old Chinese female patient who was diagnosed with chronic active Epstein-Barr virus infection more than 9 months prior and has since been presenting with cutaneous lymphoproliferative disorders mimicking hydroa vacciniforme and subsequent haemophagocytic lymphohistiocytosis. Exome sequencing suggested novel digenic heterozygous STXBP2 (c.592A > C, p.Thr198Pro) and LYST (c.830A > T, p.His277Leu) mutations.

Conclusions: This is the first case report in which adult HLH was associated with novel digenic mutations of STXBP2 and LYST combined with Epstein-Barr virus infection. It could also be the first polygenic model report, given that the pathogenicity of other mutated genes still remains unclear. We additionally conducted an in-depth, two-generation pedigree analysis to further illustrate the mode of inheritance in this case.
\end{abstract}

Keywords: Haemophagocytic lymphohistiocytosis, Digenic mutation, STXBP2, LYST, Chronic active Epstein-Barr virus infection, Case report

\section{Background}

Haemophagocytic lymphohistiocytosis (HLH) is a fatal disease resulting from primary or secondary hyper-inflammatory disorders with symptoms of persistent fever, splenomegaly, cytopenia and significant elevation of serum ferritin. Primary HLH, also known as familial HLH (FHL), is caused by a deficiency of specific genes, namely, perforin1 (PRF1), UNC13D, syntaxin 11 (STX11), syntaxin binding protein 2 (STXBP2), lysosomal trafficking regulator (LYST), RAB27A, AP3B1, SH2D1A and X-linked inhibitor of apoptosis (XIAP) as well as some other unknown genes [1-5]. Secondary HLH is a type of acquired disease associated with infections, malignancies or autoimmune disorders. STXBP2,

\footnotetext{
* Correspondence: eliteyoung@126.com

Department of Hematology, Tongji Hospital, Tongji Medical College, Huazhong University of Science and Technology, Wuhan 430030, Hubei, China
}

(c) The Author(s). 2019 Open Access This article is distributed under the terms of the Creative Commons Attribution 4.0 International License (http://creativecommons.org/licenses/by/4.0/), which permits unrestricted use, distribution, and reproduction in any medium, provided you give appropriate credit to the original author(s) and the source, provide a link to the Creative Commons license, and indicate if changes were made. The Creative Commons Public Domain Dedication waiver (http://creativecommons.org/publicdomain/zero/1.0/) applies to the data made available in this article, unless otherwise stated. (FHL-5), is located on chromosomal arm 19p13 and encodes the Munc18-2 protein that takes part in vesicle docking and fusion [6]. On the other hand, LYST (1q42) mutation is the cause of Chediak-Higashi Syndrome (CHS) and is involved in vesicle trafficking [7]. In fact, although FHL follows autosomal recessive inheritance, a heterozygous mutation may also lead to late-onset HLH in elderly patients according to the historical reports and our clinical experience [8-10]. Digenic and polygenic mutation models may demonstrate synergistic defects in cytotoxic pathways to offset the relatively low pathogenicity of heterozygotes and could lead to clinical HLH $[11,12]$.

Hereby, we report a Chinese female patient diagnosed with chronic active Epstein-Barr virus infection (CAEBV) more than 9 months earlier; the patient presented with cutaneous lymphoproliferative disorders mimicking hydroa 
vacciniforme and subsequent HLH. Exome sequencing results suggests novel digenic heterozygous STXBP2 (c.592A > C) and LYST (c.830A > T) mutations.

\section{Case presentation}

The 30-year-old Han Chinese female patient was admitted to our hospital due to symptoms of fatigue and recurrent high-grade fever $\left(>39^{\circ} \mathrm{C}\right)$ with a 4-month duration. She had presented with cutaneous lymphoproliferative disorders mimicking hydroa vacciniforme since the age of three and was diagnosed with CAEBV at Nanjing Drum Tower Hospital more than 9 months earlier. She experienced a spontaneous abortion 4 months ago. One month before her hospital visit, the patient underwent splenectomy at Nanjing for uncontrolled splenomegaly, and her postoperative pathology diagnosis suggested hypersplenism and EBV infection. She was noted to have oedematous swelling of the cheeks, eyelids and lips, and coexistent skin lesions, liver damage, pancytopenia with white blood cell (WBC) count of $1.90 \times 10^{9} / \mathrm{L}$, hypofibrinogenemia, plasma EBV-DNA $3.26 \times 10^{3}$ copies/L, EBV-DNA in peripheral blood mononuclear cells (PBMCs) of $5.93 \times 10^{4}$ copies/L, ferritin $1090.7 \mu \mathrm{g} / \mathrm{L}$, interleukin-6 (IL-6) level of $74.45 \mathrm{pg} / \mathrm{mL}$ and soluble interleukin-2 receptor (sIL-2R) level of $2083 \mathrm{U} / \mathrm{mL}$. Her bone marrow examinations failed to identify any abnormal lymphocytes or haemophagocytosis. Peripheral blood cell sorting and EBV-DNA PCR suggested predominant EBV infection with $4.68 \times 10^{5}$ copies per $2 \times 10^{5} \mathrm{~T}$ lymphocytes and $1.17 \times 10^{5}$ copies per $2 \times 10^{5}$ NK cells. NK cell killing activity decreased to $6.50 \%$ (normally $\geq 15.11 \%$ ) (Fig. 1b), and the expression levels of activated CD107a (for assessing NK cell degranulation) decreased to $33.24 \%$ (normally $\geq 40 \%$ ) (Fig. 1j). Exome sequencing demonstrated the presence of novel digenic heterozygous STXBP2 (c.592A > C) and LYST (c.830A > T) mutations as well as some variants of unknown significance with HLH (Table 1, Fig. 1). Two-generation pedigree analysis using Sanger sequencing showed that the mutations were inherited from her parents, and NK cell function tests for her parents were conducted as well (Table 2, Fig. 1). We noticed that her mother had an NK cell dysfunction which was even more severe than that of the patient herself, while her father's NK cell functions were all normal. It still remains unclear why the patient's mother did not experience any clinical symptoms all the way through, and we formulated our assumption in Discussion and Conclusions section. Because seven of the eight criteria of HLH-2004 were met [13], the patient was finally identified to have secondary HLH. X-linked lymphoproliferative disease (XLP) is a secondary disease caused by immunodeficiency-mediated EBV infection. Individuals with XLP-1 are uniquely sensitive to diseases caused by EBV, which otherwise runs a fairly benign course in most healthy individuals. HLH represents $60 \%$ of all the disease clinical features while the age of onset is within the range of $0.5-40$ years old [14]. The symptoms of HLH secondary to XLP is very similar to our case. However, the patient in our case cannot be diagnosed with XLP since we found that she and her parents had no SH2DIA or XLP1 mutations via WES and Sanger sequencing tests.

Following diagnosis, the patient was treated with persistent small dose of dexamethasone $\left(0.1 \mathrm{mg} / \mathrm{kg} \cdot \mathrm{d}^{-1}\right)$. We were able to manage the disease in the beginning, with a decreased ferritin level of $5951 \mu \mathrm{g} / \mathrm{L}$, IL-6 level of $17.78 \mathrm{pg} / \mathrm{mL}$ and normal body temperature. However, her condition was out of control one month later with the appearance of recurrent high-grade fever, rising levels of inflammatory factors, macrophage activation syndrome (MAS) and capillary leak syndrome (CLS), and we switched her therapy to the HLH-2004 protocol with etoposide and dexamethasone. DEP regimens (liposomal doxorubicin, etoposide and methylprednisolone) were also provided when HLH relapsed for the second time [15]. Ferritin levels peaked at $3222.2 \mu \mathrm{g} / \mathrm{L}$ and subsequently began to decline. Currently, the HLH of this patient has been well-controlled for a month and she is currently waiting for haematopoietic stem cell transplantation (HSCT).

For Whole Exome Sequencing (WES), DNA samples were isolated from peripheral blood. The genomic library of the proband was recovered for exome enrichment with Agilent Sure Select Human Exon v7 and was sequenced by Illumina HiSeq2500 with an average 300x coverage. The Broad Institute's Genome Analysis Toolkit was applied during the data analysis. Reads were aligned with the Illumina Chastity Filter and the Burrows Wheeler Aligner. Variants were identified by the GATK UnifiedGenotyper module. For quality control measures, coverage per base was 351x, and Q30 percentage was 92.71\%. For filtering strategy: First, generated variants were locally annotated with Annovar software under Linux system. Next, only mutations affecting amino acid sequence were filtered for further analysis (including missense, nonsense, frameshift/ non-frameshift insertion/deletion, splice-site mutation and other complex mutations). Afterwards, variants with frequency in Han population no less than 0.01 were filtered out. Then variants failed to pass quality control (reads $<20$, quality $<30$, or variants with significant strand bias) were filtered out. The mutated genes were filtered out based on classification of primary immunodeficiencies compiled by the Primary Immunodeficiency Expert Committee (PID EC) of the International Union of Immunological Societies (IUIS) [16, 17], and further tested by Sanger sequencing. Splice site variants were taken into consideration in this filter strategy while promoter regions were not. WES study was not performed on the proband's parents. Only potential pathogenic mutations in Primary Immunodeficiency (PID) associated genes (Table 1) of the 


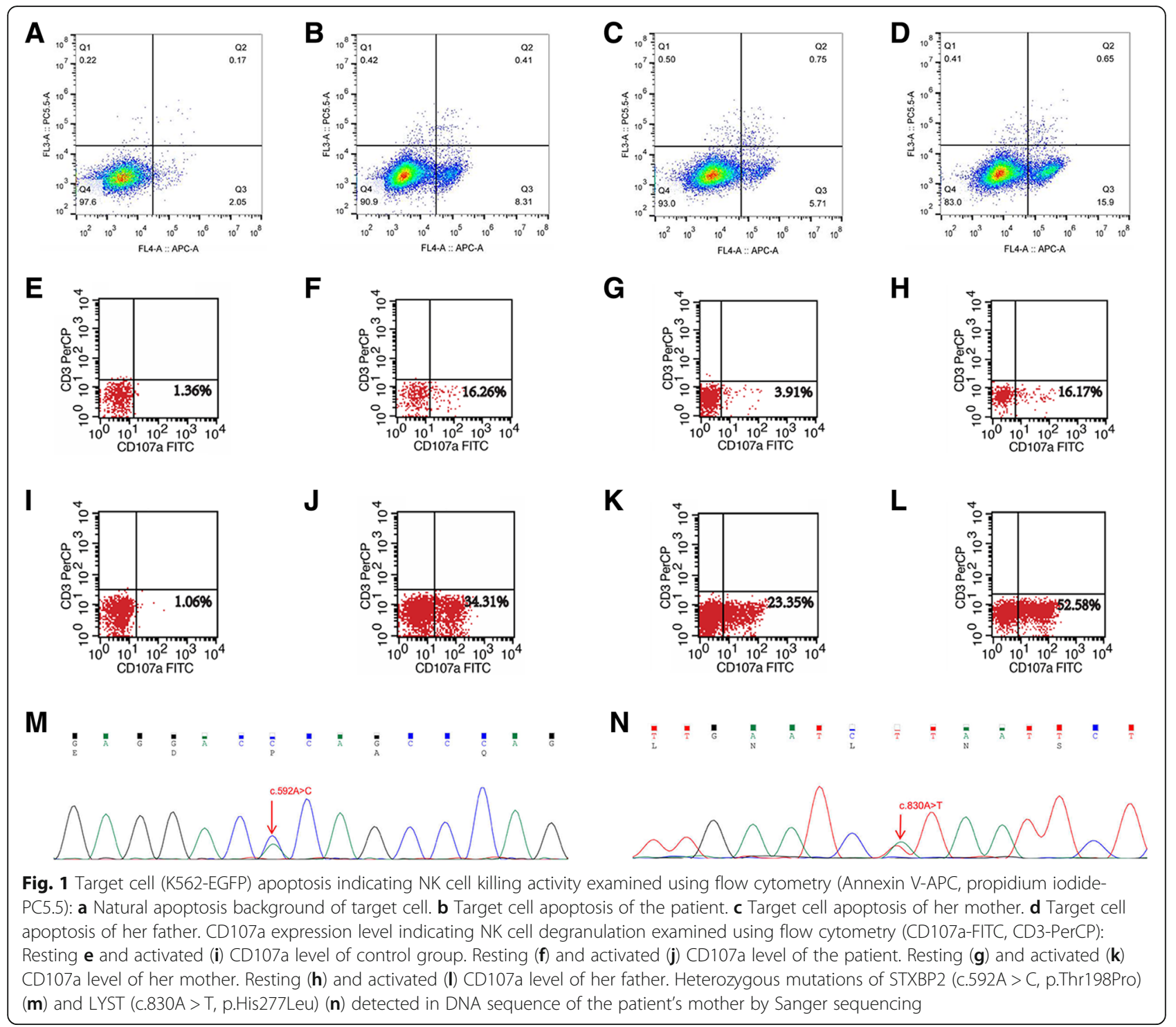

proband were identified in the proband's parents using Sanger sequencing.

\section{Discussion and conclusions}

This is the first case report of adult HLH associated with novel digenic mutations of STXBP2 and LYST, in combination with EBV infection. It is possibly the first polygenic model report as well, since the pathogenicity of other mutated genes are not yet clear. We also conducted an in-depth two-generation pedigree study to clarify the mode of inheritance in this case.

Exome sequencing results suggested that the patient has LPS-Responsive Beige-Like Anchor Protein (LRBA), Autoimmune Regulator Gene (AIRE) and Interferon Regulatory Factor 8 (IRF8) mutations in addition to STXBP2 and LYST mutations. Inherited from her mother, the $L R B A$ mutation could lead to autoimmune diseases and
EBV lymphoproliferative disease as reported in another case [18]. All the other mutations of the patients were inherited from her father. AIRE mutation is associated with autoimmunity diseases [19], while IRF8 mutation is associated with dendritic cells (DC) maturation and influences NK cell functionalities [20]. Taken together, it is difficult to verify whether or not these mutated genes are all involved in this patient's EBV infection and HLH. Whether this case follows a digenic or a polygenic model also remains a question. However, her father and uncle (with IRF8 mutation detected) are not eligible to be transplantation donor as their mutated genes could also be associated with HLH occurrence. Unrelated donor allogeneic haematopoietic stem cell transplantation (URD-HSCT) should be taken into consideration for every patient, and donors have to receive NK cell functionality testing as well in order to confirm that the 


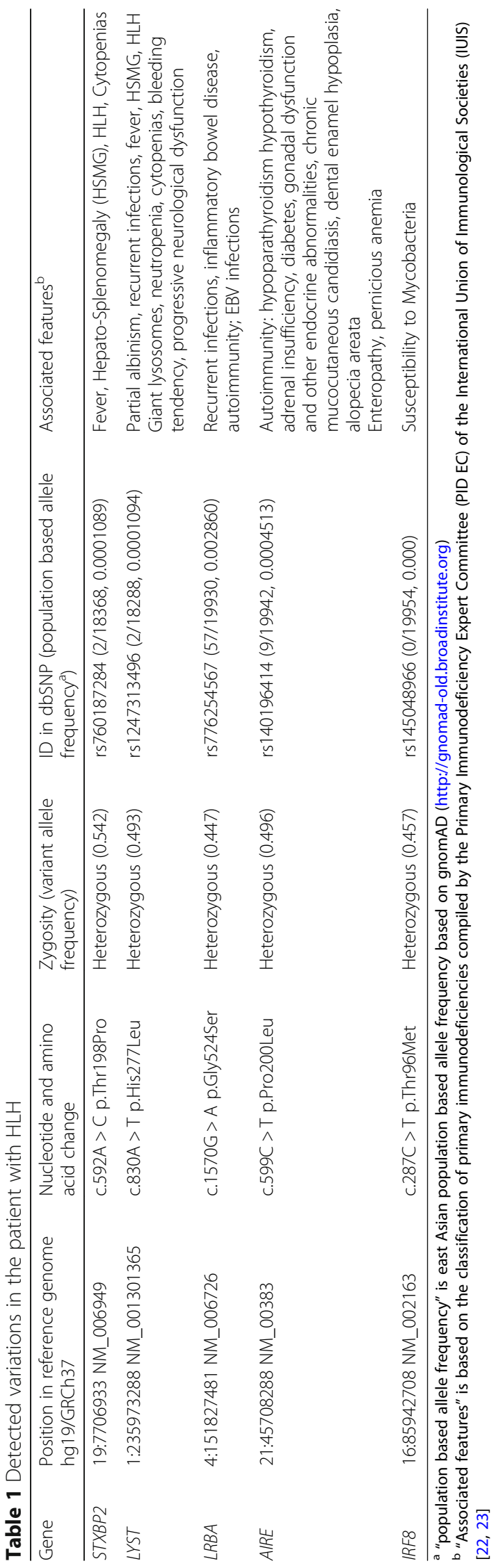


Table 2 Two-generation analysis of mutation genes and NK cell function

\begin{tabular}{|c|c|c|c|c|}
\hline & & Patient & Mother & Father \\
\hline \multirow[t]{5}{*}{ Mutation genes } & STXBP2 & + & + & - \\
\hline & LYST & + & + & - \\
\hline & $\angle R B A$ & + & + & - \\
\hline & AIRE & + & - & + \\
\hline & IRF8 & + & - & + \\
\hline \multirow[t]{3}{*}{ NK cell function } & Killing activity (normally $\geq 15.11 \%$ ) & $6.50 \%$ & $4.97 \%$ & $16.18 \%$ \\
\hline & Activated CD107a level (normally $\geq 40 \%$ ) & $33.24 \%$ & $22.60 \%$ & $51.20 \%$ \\
\hline & Resting CD107a level (normally $\geq 5 \%$ ) & $14.90 \%$ & $3.14 \%$ & $15.87 \%$ \\
\hline
\end{tabular}

+ , mutant; -, wild type

procedure could be effective thorough elimination of deficient NK cells in the patient body and thus prevent relapse [14]. Actually, among the cases (EBV+ T/NK-cell lymphoproliferative disease, infectious mononucleosis, EBV+ B-cell lymphoma, Hodgkin lymphoma, posttransplant lymphoproliferative disorders and EBV+ T/NK-cell lymphoma) we collected, the NK cell activity of most patients combined with EBV related diseases were suppressed (61/88, 69.3\%), only few of them were normal. Moreover, every HLH patient (22)'s NK cell functionality was suppressed or even absent, which slowly recovered once HLH symptoms were controlled (Author, unpublished data, 2018).

As for the reason why the proband's mother did not develop any clinical sign, here's our assumption: Firstly, the patient's mother is heterozygote. Differing from pediatric HLH that are typically due to homozygous mutations, the vast majority of EBV related adult HLH attacks are caused by heterozygous mutations. Secondly, the patient inherited other potential pathogenic genes from her father as well, except for the 2 genes inherited from her mother that are most likely pathogenic. Last, adult HLH is a type of disease which is generally caused by genetic mutations along with other acquired factors, for instance infections, tumors, etc. The patient in this case had had an abortion before being caught in the fever, which might be a precipitating factor of the HLH occurrence. We tested her mother's plasma EBV-DNA and the result was negative $\left(1.35 \times 10^{2} / \mathrm{L}\right.$ in peripheral blood mononuclear cell). The low-copy EBV of her mother appears to be a solid evidence why she did not progress into HLH or any relevant disease phenotypes, despite being found with STXBP2, LYST and other heterozygous mutations along with declined NK activity, but it could be deduced that the mother falls under the high-risk population of secondary HLH. EBV infection is the most frequent factor that triggers subsequent HLH [21]. For people with diagnosed immune deficiencies which increase their EBV susceptibility, it would be particularly difficult to achieve full virus elimination. As a result, the persistence of EBV infection would contribute to HLH and NK/T lymphoma occurrence [14]. In this case, unknown mechanisms that are able to inhibit EBV activity were probably involved in her mother's case, and the persistent EBV infection of the patient was possibly the reason why she came to a completely distinct consequence as compared with her mother.

Although progress has been made in understanding $\mathrm{HLH}$, it is still a life-threatening disease today. We report this case for the illustration of possible digenic and polygenic mode of inheritance of HLH that have been previously confirmed in the mouse model only [12]. We are looking forward to advancing our understanding and offering a higher level of individualization of HLH treatments in the future, apart from classic chemotherapy and HSCT. Cord blood NK cell transplantation is expected to be capable of repairing damaged NK cells $[22,23]$, and monoclonal antibodies (mAb), for example the anti-sCD25 mAb, could potentially target certain cytokines that are perceived as unmanageable [24]. In the future, customized gene therapy may provide solutions for the treatment of HLH.

\section{Abbreviations \\ AIRE: Autoimmune regulator gene; CAEBV: Chronic active Epstein-Barr virus infection; CHS: Chediak-Higashi Syndrome; CLS: Capillary leak syndrome; DC: Dendritic cell; FHL: Familial haemophagocytic lymphohistiocytosis; HLH: Haemophagocytic lymphohistiocytosis; HSCT: Haematopoietic stem cell transplantation; IL-6: Interleukin-6; IRF8: Interferon regulatory factor 8; \\ LRBA: Lipopolysaccharide-responsive beige-like anchor protein; LYST: Lysosomal trafficking regulator; mAb: Monoclonal antibodies; MAS: Macrophage activation syndrome; PBMC: Peripheral blood mononuclear cell; PID EC: Primary Immunodeficiency Expert Committee; PID: Primary Immunodeficiency; PRF1: Perforin 1; slL-2R: Soluble interleukin-2 receptor; STX11: Syntaxin 11; STXBP2: Syntaxin binding protein 2; URD-HSCT: Unrelated donor allogeneic haematopoietic stem cell transplantation; WBC: White blood cell; WES: Whole Exome Sequencing; XIAP: X-linked inhibitor of apoptosis; XLP: X-linked lymphoproliferative disease}

\section{Acknowledgements}

Not applicable.

\section{Funding}

This case report is financed by National Nature Science Funds of China (81500137). The role of funding body was to sponsor the two-generation pedigree analysis, the WES and the other tests we conducted for this case.

\section{Availability of data and materials}

The datasets generated and analysed during the current study are not publicly available [because the data relate to a human research participant, it may not be appropriate to make them publicly available] but are available from the corresponding author on reasonable request. 


\section{Authors' contributions}

SL performed the clinical assessment of the patient and wrote the manuscript. ZW, GJ, SK and LH analysed and interpreted the data related to the case report; YY conceived the work, critically revised the manuscript, and gave final approval of the version to be published. All authors have read and approved the final manuscript for publication.

\section{Ethics approval and consent to participate}

The publication of this manuscript has been reviewed and approved by the Tongji Hospital, Tongji Medical College, and Huazhong University of Science and Technology institutional review board.

\section{Consent for publication}

The patient and her family have provided written consent for the publication of this manuscript.

\section{Competing interests}

The authors declare that they have no competing interests.

\section{Publisher's Note}

Springer Nature remains neutral with regard to jurisdictional claims in published maps and institutional affiliations.

Received: 19 October 2018 Accepted: 13 February 2019

Published online: 19 February 2019

\section{References}

1. Usmani GN, Woda BA. Advances in understanding the pathogenesis of $\mathrm{HLH}$. Br J Haematol. 2013;161:609-22.

2. Feldmann J, Callebaut I, Raposo G, Certain S, Bacq D, Dumont C, et al. Munc134 is essential for cytolytic granules fusion and is mutated in a form of familial hemophagocytic lymphohistiocytosis (FHL3). Cell. 2003;115:461-73.

3. Zur SU, Schmidt S, Kasper B, Beutel K, Diler AS, Henter Jl, et al. Linkage of familial hemophagocytic lymphohistiocytosis (FHL) type-4 to chromosome $6 q 24$ and identification of mutations in syntaxin 11. Hum Mol Genet. 2005; 14:827-34.

4. Zur SU, Rohr J, Seifert W, Koch F, Grieve S, Pagel J, et al. Familial hemophagocytic lymphohistiocytosis type 5 (FHL-5) is caused by mutations in Munc18-2 and impaired binding to syntaxin 11. Am J Hum Genet. 2009:85:482-92

5. Stepp SE, Dufourcq-Lagelouse R, Le Deist F, Bhawan S, Certain S, Mathew $P A$, et al. Perforin gene defects in familial hemophagocytic lymphohistiocytosis. Science. 1999;286:1957-9.

6. Seo JY, Lee KO, Yoo KH, et al. Prevalence of type 5 familial hemophagocytic lymphohistiocytosis in Korea and novel mutations in STXBP2. Clin Genet. 2016;89:222-7

7. Kaplan J, De Domenico I. Chediak-Higashi syndrome. Curr Opin Hematol. 2008:15:22-9.

8. Zhang K, Jordan MB, Marsh RA, et al. Hypomorphic mutations in PRF1, MUNC13-4, and STXBP2 are associated with adult-onset familial HLH. Blood. 2011;118:5794-8

9. Beaty AD, Weller C, Levy B, Vogler C, Ferguson WS, Bicknese A, et al. A teenage boy with late onset hemophagocytic lymphohistiocytosis with predominant neurologic disease and perforin deficiency. Pediatr Blood Cancer. 2008;50:1070-2.

10. Gao L, Zhu L, Huang L, Zhou J. Synergistic defects of UNC13D and AP3B1 leading to adult hemophagocytic lymphohistiocytosis. Int J Hematol. 2015;102:488-92.

11. Zhang K, Chandrakasan S, Chapman H, Valencia CA, Husami A, Kissell D, et al. Synergistic defects of different molecules in the cytotoxic pathway lead to clinical familial hemophagocytic lymphohistiocytosis. Blood. 2014;124: $1331-4$

12. Sepulveda FE, Garrigue A, Maschalidi S, et al. Polygenic mutations in the cytotoxicity pathway increase susceptibility to develop HLH immunopathology in mice. Blood. 2016;127:2113-21.

13. Henter J, Horne A, Egeler RM, Filipovich AH, Imashuku S, Ladisch S, Mcclain K, Webb D, Winiarski J, Janka G. HLH-2004: diagnostic and therapeutic guidelines for hemophagocytic lymphohistiocytosis. Pediatr Blood Cancer. 2007:48(2):124-31.

14. Tangye SG, Palendira U. Human immunity against EBV-lessons from the clinic. J Exp Med. 2017;214:269-83.
15. Wang J, Wang $Y$, Wu L, et al. PEG-aspargase and DEP regimen combination therapy for refractory Epstein-Barr virus-associated hemophagocytic lymphohistiocytosis. J Hematol Oncol. 2016;9:84.

16. Picard C, Al-Herz W, Bousfiha A, et al. Primary immunodeficiency diseases: an update on the classification from the International Union of Immunological Societies Expert Committee for primary immunodeficiency 2015. J Clin Immunol. 2015;35:696-726.

17. Al-Herz W, Bousfiha A, Casanova JL, Chatila T, Conley ME, CunninghamRundles $C$, et al. Primary immunodeficiency diseases: an update on the classification from the international union of immunological societies expert committee for primary immunodeficiency. Front Immunol. 2014;5:162.

18. Cohen JI. Primary Immunodeficiencies Associated with EBV Disease. Curr Top Microbiol Immunol. 2015;390:241-265.

19. Zhao B, Chang L, Fu H, et al. The role of autoimmune regulator (AIRE) in peripheral tolerance. J Immunol Res. 2018:2018:3930750.

20. Adams NM, Lau CM, Fan X, et al. Transcription Factor IRF8 Orchestrates the Adaptive Natural Killer Cell Response. Immunity. 2018;48:1172-82 e6.

21. Yachie A, Kanegane H. Epstein-Barr virus-associated T-/natural killer cell lymphoproliferative diseases. Semin Hematol. 2003;40:124-32.

22. Hagihara M, Gansuvd B, Ueda Y, et al. Killing activity of human umbilical cord blood-derived TCRValpha24(+) NKT cells against normal and malignant hematological cells in vitro: a comparative study with NK cells or OKT3 activated T lymphocytes or with adult peripheral blood NKT cells. Cancer Immunol Immunother. 2002;51:1-8.

23. Sarvaria A, Jawdat D, Madrigal JA. Umbilical cord blood natural killer cells, their characteristics, and potential clinical applications. Front Immunol. 2017;8:329.

24. Olin RL, Nichols KE, Naghashpour M, et al. Successful use of the anti-CD25 antibody daclizumab in an adult patient with hemophagocytic lymphohistiocytosis. Am J Hematol. 2008;83:747-9.

\section{Ready to submit your research? Choose BMC and benefit from:}

- fast, convenient online submission

- thorough peer review by experienced researchers in your field

- rapid publication on acceptance

- support for research data, including large and complex data types

- gold Open Access which fosters wider collaboration and increased citations

- maximum visibility for your research: over $100 \mathrm{M}$ website views per year

At BMC, research is always in progress.

Learn more biomedcentral.com/submissions 